\title{
STUDY OF REMOVAL MECHANISMS OF METAL ELEMENTS FROM SEAWATER USING RADIOACTIVE MULTITRACERS
}

\author{
SHAO YONG CHEN", ${ }^{2,)}$ SHIZUKO AMBE", YOSHTAKA OHKUBO ${ }^{*}$, MASAKO IWAMOTO", \\ YOSHIO KOBAYASHI", NOBURU TAKEMATSU*, and FUMTTOSHI AMBE ${ }^{*}$ \\ a)The Institute of Physical and Chemical Research (RIKEN), Wako-shi, Saitama 351-01, Japan \\ b)South China Sea Institute of Oceanology, Academia Sinica, Guangzhou 510301, China
}

\begin{abstract}
The adsorption of metal elements on hydrated ferric oxide, clay minerals, and marine sediments from artificial seawater is studied using radioactive multitracers produced by RIKEN Ring Cyclotron. The distribution coefficients (Kd) of $\mathrm{Co}, \mathrm{Ga}, \mathrm{Rb}, \mathrm{Sr}, \mathrm{Y}, \mathrm{Zr}, \mathrm{Nb}, \mathrm{Mo}, \mathrm{Ru}, \mathrm{Rh}, \mathrm{Pd}, \mathrm{Ag}, \mathrm{In}, \mathrm{Sn}, \mathrm{Eu}, \mathrm{Gd}, \mathrm{Tb}, \mathrm{Tm}, \mathrm{Yb}$, $\mathrm{Lu}, \mathrm{Hf}, \mathrm{Re}$ and $\mathrm{Hg}$ were determined. The order of $\mathrm{Kd}$ for each element is summarized as follows: hydrated ferric oxide > deep-sea sediment $>$ montmorillonite $\geq$ nearshore sediment $\geq$ kaolinite. It is inferred from the observation that hydrated ferric oxide plays an important role in removing metal elements from seawater.
\end{abstract}

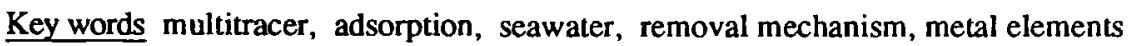

Removal mechanisms of elements from the ocean have been discussed by many researchers[1-9]. It was suggested that the partition of elements between particulate solid phases (pelagic clays, manganese and iron oxides, organisms, etc.) and seawater is, for the first approximation, controlled by the affinity of cations and oxyanions for the hydrolyzed particulate surfaces[2,9]. Adsorption of metal elements on hydrated ferric oxide, clay minerals (montmorillonite and kaolinite), and marine sediments (deep-sea and nearshore sediments) from artificial seawater is studied by a radioactive multitracer method. On the basis of the distribution coefficients of metal elements for the particulates, the ultimate removal mechanism of metal elements from seawater is discussed.

\section{MATERIALS AND METHODS}

Adsorbents Hydrated ferric oxide was prepared by hyrolyzing ferric ions at pH 7.5. Deep-sea and nearshore sediments were obtained from the Penrhyn Basin ( $12^{\circ} 26.44^{\prime} \mathrm{S}, 157^{\circ} 57.20 \mathrm{~W}$, depth 5351 meters) and Suruga Bay $\left(34^{\circ} 44.52 \mathrm{~N}, 169^{\circ} 27.05 \mathrm{E}\right.$, depth ca. 600 meters), respectively. The adsorbents were stored in artificial seawater as a suspension $\left(2 \mathrm{mg} \mathrm{cm}^{-3}\right)$.

Multitracer The multitracers were separated from gold and copper foils irradiated with a ${ }^{14} \mathrm{~N}$ beam of 135 $\mathrm{MeV} /$ nucleon accelerated by the RIKEN Ring Cyclotron in a carrier- and salt-free state[10]. The multitracers were stored as $6 \mathrm{~mol} \mathrm{dm}^{-3} \mathrm{HCl}$ solutions.

Adsorption procedure Artificial seawater and a small amount of a multitracer solution were put in a polyethylene bottle. After the $\mathrm{pH}$ value was adjusted to 7.5 with a $1 \mathrm{~mol} \mathrm{dm}^{-3} \mathrm{Na}_{2} \mathrm{CO}_{3}$ solution, the adsorbent suspension was added to the solution. Its $\mathrm{pH}$ value was readjusted to 7.5 when necessary. The suspension was shaken in an 8-shape mode with a shaker at $25^{\circ} \mathrm{C}$. After centrifugation, a portion of the supernatant solution was pipetted. The $\gamma$-ray spectrum of radioactive nuclides in the solutions were measured with a Ge detector. The distribution coefficients (Kd) for each nuclide were calculated as follows:

$\mathrm{Kd}=($ Aads $/ \mathrm{m}) /($ Asoln $/ \mathrm{V})=((\mathrm{Ai}-\mathrm{Af}) / \mathrm{Af})(\mathrm{V} / \mathrm{m})$.

Aads and Asoln are the radioactivity in the adsorbent and the solution after adsorption equilibrium, respectively. $V$ is volume of the solution $\left(\mathrm{cm}^{-3}\right)$. $\mathrm{m}$ is the amount of the adsorbent $(\mathrm{g})$. Ai and Af are the radioactivity in the solution 
before and after adsorption equilibrium, respectively.

\section{RESULTS AND DISCUSSION}

The distribution coefficients (Kd) of $\mathrm{Co}, \mathrm{Ga}, \mathrm{Rb}, \mathrm{Sr}, \mathrm{Y}, \mathrm{Zr}, \mathrm{Nb}, \mathrm{Mo}, \mathrm{Ru}, \mathrm{Rh}, \mathrm{Pd}, \mathrm{Ag}$, In, Sn, Eu, Gd, Tb, $\mathrm{Tm}, \mathrm{Yb}, \mathrm{Lu}, \mathrm{Hf}, \mathrm{Re}$ and $\mathrm{Hg}$ at $\mathrm{pH} 7.5$ and at $25^{\circ} \mathrm{C}$ are given in TABLE 1 . The order of $\mathrm{Kd}$ for each element is summarized as follows: hydrated ferric oxide > deep-sea sediment $>$ montmorillonite $\geq$ nearshore sediment $\geq$ kaolinite. The deep-sea sediment used in this study is red clay containing about $1.5 \%$ iron oxide and $0.5 \%$ manganese oxide. The nearshore sediment is green clay and contains a much smaller amount of iron and manganese oxides than does the deep-sea sediment. It is evident that the adsorbent rich in the oxides has high distribution coefficients. Consequently, it is inferred that hydrated ferric oxide plays a more important role than does clay minerals (kaolinite and montmorillonite) in removing metal elements from seawater and interstitial water in marine environments.

The logarithmic plots of distribution coefficients $(\mathrm{Kd})$ versus electron binding energy $\mathrm{I}_{\mathrm{z}}$, the energy necessary to remove one electron from the metal ion in question) for the hydrated ferric oxide and deep-sea sediment are shown in Fig. 1. The distribution coefficients of elements between the particulates and seawater tend to increase with

TABLE 1. Distribution coefficients of metal elements for hydrated ferric oxide, deep-sea sediment, montmorillonite, nearshore sediment and kaolinite $\left(\mathrm{cm}^{3} \mathrm{mg}^{-1}\right)^{*}$

\begin{tabular}{|c|c|c|c|c|c|}
\hline & H.F.O. $* *$ & D. sediment & Montmorillonite & N. sediment & Kaolinite \\
\hline $\mathrm{Co}$ & $1.3 \times 10^{5}$ & $1.5 \times 10^{5}$ & $8.5 \times 10^{3}$ & $1.0 \times 10^{4}$ & $1.3 \times 10^{3}$ \\
\hline $\mathrm{Ga}$ & $1.4 \times 10^{6}$ & $2.8 \times 10^{5}$ & $4.3 \times 10^{4}$ & $6.4 \times 10^{4}$ & $3.0 \times 10^{4}$ \\
\hline $\mathrm{Rb}$ & $2.9 \times 10^{2}$ & $1.2 \times 10^{3}$ & $3.3 \times 10^{2}$ & $1.7 \times 10^{2}$ & $7.4 \times 10^{2}$ \\
\hline $\mathrm{Sr}$ & $2.6 \times 10^{3}$ & $1.9 \times 10^{3}$ & $1.0 \times 10^{3}$ & $2.6 \times 10^{2}$ & $4.8 \times 10^{2}$ \\
\hline $\mathrm{Y}$ & $2.6 \times 10^{5}$ & $1.5 \times 10^{5}$ & $6.4 \times 10^{4}$ & $1.0 \times 10^{4}$ & $5.0 \times 10^{4}$ \\
\hline $\mathrm{Zr}$ & $9.1 \times 10^{4}$ & $1.1 \times 10^{4}$ & $8.5 \times 10^{3}$ & $5.3 \times 10^{3}$ & $3.5 \times 10^{3}$ \\
\hline $\mathrm{Nb}$ & $5.3 \times 10^{4}$ & $5.8 \times 10^{3}$ & $6.3 \times 10^{3}$ & $7.0 \times 10^{3}$ & $2.8 \times 10^{3}$ \\
\hline Mo & $6.4 \times 10^{3}$ & $5.5 \times 10^{2}$ & - & - & $7.1 \times 10^{2}$ \\
\hline $\mathrm{Ru}$ & $1.5 \times 10^{4}$ & $1.3 \times 10^{4}$ & $5.2 \times 10^{3}$ & $3.8 \times 10^{3}$ & $4.0 \times 10^{3}$ \\
\hline $\mathrm{Rh}$ & $8.3 \times 10^{3}$ & $2.6 \times 10^{3}$ & $4.1 \times 10^{3}$ & $1.3 \times 10^{3}$ & $1.9 \times 10^{3}$ \\
\hline $\mathrm{Pd}$ & $1.3 \times 10^{4}$ & $7.7 \times 10^{3}$ & $2.9 \times 10^{3}$ & $9.1 \times 10^{3}$ & $9.3 \times 10^{3}$ \\
\hline $\mathrm{Ag}$ & - & $2.5 \times 10^{3}$ & $4.4 \times 10^{3}$ & $3.5 \times 10^{3}$ & $9.1 \times 10^{3}$ \\
\hline In & $1.5 \times 10^{4}$ & $7.2 \times 10^{3}$ & $2.0 \times 10^{4}$ & $1.9 \times 10^{4}$ & $1.9 \times 10^{4}$ \\
\hline $\mathrm{Sn}$ & $2.2 \times 10^{4}$ & $7.2 \times 10^{3}$ & $8.4 \times 10^{3}$ & $2.7 \times 10^{3}$ & $6.5 \times 10^{3}$ \\
\hline $\mathrm{Eu}$ & $2.5 \times 10^{5}$ & $3.0 \times 10^{5}$ & $2.4 \times 10^{5}$ & $3.6 \times 10^{5}$ & $1.7 \times 10^{5}$ \\
\hline $\mathrm{Gd}$ & $5.7 \times 10^{5}$ & $4.9 \times 10^{5}$ & $1.4 \times 10^{5}$ & $1.7 \times 10^{5}$ & $1.4 \times 10^{5}$ \\
\hline $\mathrm{Tb}$ & $1.0 \times 10^{5}$ & $1.5 \times 10^{4}$ & $5.8 \times 10^{4}$ & $7.2 \times 10^{3}$ & $2.8 \times 10^{4}$ \\
\hline $\operatorname{Tm}$ & $3.7 \times 10^{5}$ & $5.7 \times 10^{5}$ & $6.6 \times 10^{4}$ & $1.0 \times 10^{5}$ & $4.7 \times 10^{4}$ \\
\hline $\mathrm{Yb}$ & $5.2 \times 10^{4}$ & $4.3 \times 10^{4}$ & $3.3 \times 10^{4}$ & $4.0 \times 10^{4}$ & $4.4 \times 10^{4}$ \\
\hline $\mathrm{Lu}$ & $2.6 \times 10^{5}$ & $2.6 \times 10^{5}$ & $5.6 \times 10^{4}$ & $1.0 \times 10^{5}$ & $5.8 \times 10^{4}$ \\
\hline Hf & $1.0 \times 10^{5}$ & $1.1 \times 10^{4}$ & $2.1 \times 10^{4}$ & $4.4 \times 10^{3}$ & $1.1 \times 10^{4}$ \\
\hline $\operatorname{Re}$ & $1.3 \times 10^{4}$ & - & $9.7 \times 10^{3}$ & - & $1.2 \times 10^{3}$ \\
\hline $\mathrm{Hg}$ & $1.2 \times 10^{5}$ & $5.6 \times 10^{4}$ & $1.1 \times 10^{5}$ & $3.7 \times 10^{4}$ & $2.6 \times 10^{4}$ \\
\hline
\end{tabular}





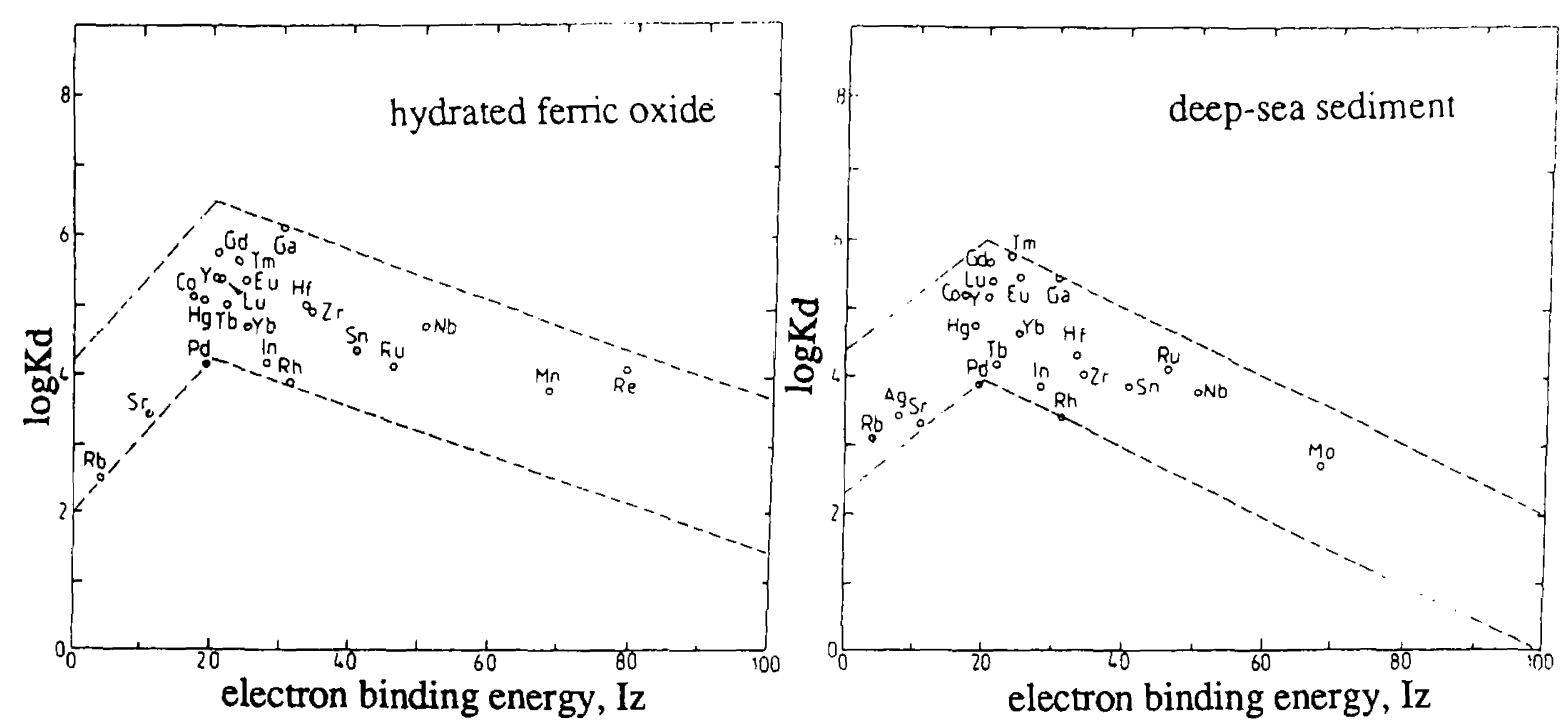

Fig. 1. Logarithmic plot of distribution coefficients $(\mathrm{Kd})$ of metal elements for hydrated ferric oxide and deep-sea sediment versus the electron binding energies (Iz).

increasing $\mathrm{I}_{z}$ 'S from free cationic elements to strongly hydrolyzed cations and then dccrease to oxyanionic elcments. The results obtained agree well with the observed partition of elements between pelagic clays and seawater $(2,4]$. According to Martin and Whitfield[5], the logarithms of distribution coefficients (Kd) of metal elements for hydrated ferric oxide and kaolinite are plotted against the mean oceanic residence time ( $\tau$ ) of metal elements (Fig. 2). The distribution coefficients are well correlated with the mean oceanic residence time.

From the surface complexation model, Balistrieri et al.[11] derived the relationship between the residence time of the sinking particulate matter $\left(\tau_{\mathrm{p}}\right)$ and the mean oceanic residence time of metal elements $(\tau)$ as follows:

$$
\tau / \tau_{\mathrm{p}}=\left([\mathrm{Me}]+\sum^{\mathrm{n}} \sum^{\mathrm{j}}[\mathrm{Mel} \text { nj] }]+[\mathrm{Me}] \mathrm{ads}\right) /[\mathrm{Me}] \mathrm{ads} .
$$

Eq. (1) is changed to Eqs. (2), (3) and (4).

$$
\begin{aligned}
& \tau / \tau_{p}=\left([\mathrm{Me}]+\sum^{n} \sum^{j}[\mathrm{MeLnj}]\right) /[\text { Me }] \text { ads }+1=\mathrm{C} / \mathrm{Kd}+1 \\
& \left(\tau-\tau_{\mathrm{p}}\right) / \tau_{\mathrm{p}}=\mathrm{C} / \mathrm{Kd} \\
& \log \left(\tau-\tau_{\mathrm{p}}\right)=-\log \mathrm{Kd}+\log \tau_{\mathrm{p}}+\log \mathrm{C}
\end{aligned}
$$
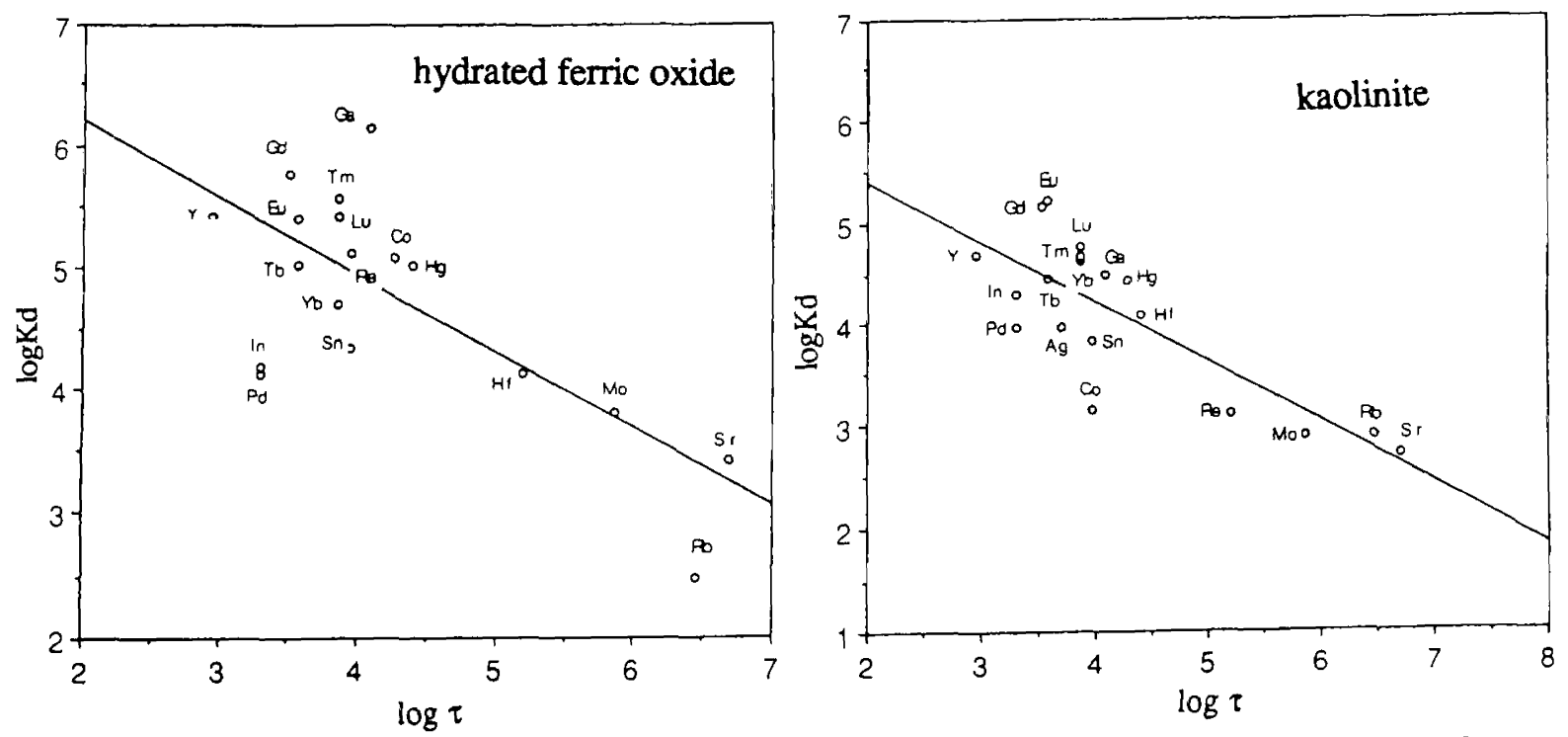

Fig. 2. Logarithmic plot of distribution coefficients $(\mathrm{Kd})$ of metal elements for hydrated ferric oxide and kaolinite versus the mean oceanic residence times $(\tau)$ of metal elements. 
$\tau_{p}(0.365$ year $)[11]$ is overwhelmingly smaller than $\tau$, and then Eq. (4) can be simplified to Eq. (5):

$\log \tau=-\log \mathrm{Kd}+\log \mathrm{C}^{\prime}$

By the method of least squares, the following relationships from plots as in Fig. 2 are obtained:

$\begin{array}{rlrl}\log \tau & =-0.61 \operatorname{logKd}+7.4 & & \text { for hydrated ferric oxide } \\ \log \tau=-0.60 \operatorname{logKd}+6.6 & & \text { for kaolinitc } \\ \log \tau=-0.51 \operatorname{logKd}+6.4 & & \text { for montmorillonite } \\ \log \tau=-0.54 \operatorname{logKd}+6.7 & & \text { for deep-sea sediment } \\ \log \tau=-0.51 \operatorname{logKd}+8.0 & \text { for nearshore sediment. }\end{array}$

It is concluded that the adsorption of metal elements on hydrated ferric oxide and clay minerals is a very important removal mechanism of metal elemenets from the ocean.

\section{REFERENCES}

1. M. D.Kurmar, Mar. Chem., 14, 121 (1983).

2. Y. H. Li, Geochim. Cosmochim. Acta, 45,1659 (1981).

3. Y. H. Li, Geochim. Cosmochim. Acta, 46, 1993 (1982).

4. Y. H. Li , Geochim. Cosmochim. Acta, submitted.

5. J.-M. Martin and M. Whitfield, Trace Metals in Seawater, ed. C. S. Wong et. al., Plenum press, New York, p. 265 (1983).

6. N. Takematsu, J. Oceanogr. Soc. Japan, 35, 36 (1979).

7. N.Takematsu, Y. Sato, and S. Okabe, Mar. Chem., 26, 41 (1989).

8. M. Whitfield and D. R. Tumer, Nature, 278, 132 (1979).

9. M. Whitfield and D. R. Tumer, Trace Metals in Seawater, ed. C. S. Wong et. al., Plenum Press, New York, p. 719 (1983).

10. S. Ambe, S. Y. Chen, Y. Ohkubo, Y. Kobayashi, M. Iwamoto, M. Yanokura, and F. Ambe, Chem. Lett., 149 (1991).

11. L. Balistrieri, P. G. Brewer, and W. Murray, Deep-sea Res., 28A, 101 (1981). 